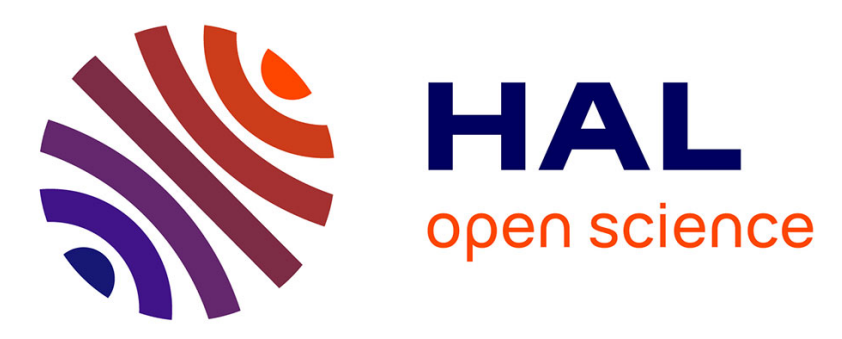

\title{
Hardening and Thermal stability of nanocrystalline AlMg4.8 powder
}

Marco Hüller, Johannes Vlcek, Markus Dinkel, Heinz Werner Höppel, Mathias Goeken

\section{- To cite this version:}

Marco Hüller, Johannes Vlcek, Markus Dinkel, Heinz Werner Höppel, Mathias Goeken. Hardening and Thermal stability of nanocrystalline AlMg4.8 powder. Philosophical Magazine, 2008, 88 (08), pp.1209-1226. 10.1080/14786430802089854 . hal-00513891

\section{HAL Id: hal-00513891 https://hal.science/hal-00513891}

Submitted on 1 Sep 2010

HAL is a multi-disciplinary open access archive for the deposit and dissemination of scientific research documents, whether they are published or not. The documents may come from teaching and research institutions in France or abroad, or from public or private research centers.
L'archive ouverte pluridisciplinaire HAL, est destinée au dépôt et à la diffusion de documents scientifiques de niveau recherche, publiés ou non, émanant des établissements d'enseignement et de recherche français ou étrangers, des laboratoires publics ou privés. 


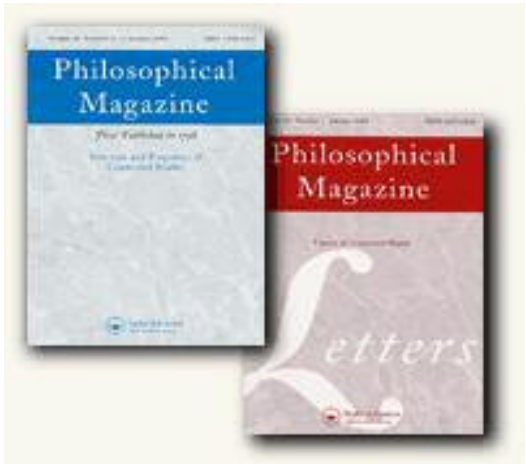

Hardening and Thermal stability of nanocrystalline AIMg4.8 powder

\begin{tabular}{|c|c|}
\hline Journal: & Philosophical Magazine \& Philosophical Magazine Letters \\
\hline Manuscript ID: & TPHM-07-Aug-0244.R2 \\
\hline Journal Selection: & Philosophical Magazine \\
\hline $\begin{array}{r}\text { Date Submitted by the } \\
\text { Author: }\end{array}$ & 24-Mar-2008 \\
\hline Complete List of Authors: & $\begin{array}{l}\text { Hüller, Marco; EADS Innovation Works Germany, Metallic } \\
\text { Technologies \& Surface Engineering } \\
\text { VIcek, Johannes; EADS Innovation Works Germany, Metallic } \\
\text { Technologies \& Surface Engineering } \\
\text { Dinkel, Markus; University Erlangen, WWI } \\
\text { Höppel, Heinz Werner; University Erlangen, WWI } \\
\text { Göken, Mathias; University Erlangen, WWI }\end{array}$ \\
\hline Keywords: & aluminium alloys, ball-milling, DSC, nanostructured materials \\
\hline Keywords (user supplied): & Hall-Petch effect \\
\hline
\end{tabular}

\section{(s) ScholaroNE \\ Manuscript Central}


Philosophical Magazine Vol. X, No. X, Month 2004, xxx-xxx

\title{
Hardening and thermal stability of nanocrystalline AlMg4.8 powder
}

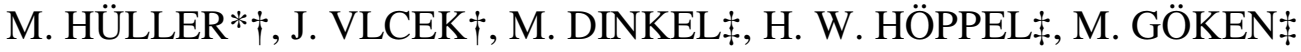 \\ $\dagger$ EADS Innovation Works Germany, 81663 München, Germany \\ † Universität Erlangen-Nürnberg, Lehrstuhl WWI, Martensstraße 5, 91058 Erlangen, Germany \\ *Corresponding author. Email: M.Hueller@web.de ${ }^{1}$
}

Abstract

Ball milled nanocrystalline AlMg4.8 powder was investigated in terms of hardening and thermal stability. The validity of the Hall-Petch relation was confirmed down to the minimum grain size of $\sim 44 \mathrm{~nm}$. Prolonged milling in the range of the minimum grain size still increased the hardness. This development was discussed in terms of contamination effects and the influence of full and partial dislocations. Concerning thermal stability, recovery processes occur in the range of $100-$ $230{ }^{\circ} \mathrm{C}$ while substantial grain growth starts at a temperature of $\sim 250{ }^{\circ} \mathrm{C}$. The enthalpy release for recovery was detected to be $\sim 39 \mathrm{~J} / \mathrm{mol}$ and $\sim 208 \mathrm{~J} / \mathrm{mol}$ for grain growth. Dynamic strain aging was indicated by an activation energy for recovery of $Q \sim 120 \mathrm{~kJ} / \mathrm{mol}$. The activation energy of grain growth was calculated by means of the Kissinger theory $(\mathrm{Q}=200-210 \mathrm{~kJ} / \mathrm{mol})$ and using the results of static grain growth $(\mathrm{Q}=204 \mathrm{~kJ} / \mathrm{mol})$.

Keywords: Aluminium alloys, Ball milling, Nanocrystalline materials, Differential scanning calorimetry, Hall-Petch

\section{Introduction}

Nanocrystalline (NC) materials feature grain sizes smaller than $100 \mathrm{~nm}$. Gleiter [1] was one of the first who reported the outstanding mechanical and physical properties of this group of materials in contrast to conventional coarse-grained materials. This behaviour is due to the extremely high volume fraction of grain boundaries. The excess Gibbs free energy stored in the two-dimensional defects is the reason for a thermodynamically non-equilibrium state. The stability of NC materials with respect to grain growth is often discussed in literature [2]. When NC materials are investigated, the synthesis process always has to be considered, as each route introduces specific contaminations. Impurities and inhomogeneities can strongly alter the mechanical behaviour and especially the thermal stability [3]. The enhanced resistance to grain growth is associated to compositional parameters as well as to microstructural inhomogeneities as vacancies [4]. NC

*Corresponding author. †Email: M.Hueller@web.de 


\section{Hüller et al.}

materials can be synthesized by different methods for instance by inert gas condensation, pulsed electro deposition, chemical and physical vapour deposition and ball milling followed by a consolidation process. The latter is applied in the present study due to the high versatility of the ball milling process yielding very low grain size values in a huge variety of crystalline materials [5]. But synthesis of nanostructured materials via powder metallurgy comprising ball milling can introduce a high quantity of impurities. One major source is the attrition of the milling tools; the other is the incorporation of gases due to the generation of activated surfaces in the milled powder. Therefore these factors have to be thoroughly monitored regarding the evaluation of the mechanical properties.

The validity of the Hall-Petch relationship, describing the hardness/strength increase as a function of grain size is still under discussion $[6,7]$. In recent years it was found that this equation holds for polycrystalline materials in a wide range concerning their grain size. In fact for materials with very small grains, in the range of less than approximately $100 \mathrm{~nm}$, its validity is not clear as the deformation mechanisms change and contamination effects increase. Mechanisms like grainboundary sliding, grain boundary diffusion and mechanical twinning are supposed to dominate, rather than dislocation based plasticity. Twinning is associated with the emission of partial dislocations, which are favoured from an energetic point of view. Thus a breakdown of the relationship and even an inversion of this relationship have been discussed [8-11]. In contrast, dislocation pile-up was observed recently during TEM in situ straining by Youssef et al. [12] in $\mathrm{NC} \mathrm{Cu}$. A finding if the Hall-Petch relation is still valid for the $\mathrm{NC}$ regime would also elucidate some questions concerning the character of thermal activated processes.

The present study addresses the investigation of the microstructural evolution and the change in the composition during milling of the alloy AlMg4.8. The thermal stability of the milled NC powder is studied quantitatively by means of DSC measurements and grain size evolution detected by XRD and TEM respectively. The results concerning microstructural changes during synthesis and annealing are related to the micro-hardness. The sensitivity of the mechanical properties of NC materials concerning impurities was also evaluated.

\section{Experimental procedure}

The binary alloy powder AlMg4.8 was synthesised by inert gas atomisation carried out by ECKA Granules. The powder showed an average particle size of $50 \mu \mathrm{m}$. The chemical composition was determined by inductively coupled plasma (ICP) measurement. The gas content was investigated by means of hot gas extraction.

Milling was performed in the planetary ball mill "pulverisette6" from Fritsch using hardened steel vial and balls. The ball to powder weight ratio was 5:1, whereas no process control agent was added. To reduce contaminations during milling all experiments were carried out under Argon environment. The milling times given in the present study are the total of 15 min milling steps. The incremental procedure of $15 \mathrm{~min}$ milling and a phase of $30 \mathrm{~min}$ cooling avoided strong temperature increase. The powder output is around 6 wt. \% lower than the input which is mainly attributed due to the adherence of the ground material on the milling balls.

All investigations concerning the thermal stability were carried out on the powder AlMg4.8 milled for $8 \mathrm{~h}$. Annealing experiments of $0.5,3$ and $100 \mathrm{~h}$ duration were accomplished in the temperature range $150^{\circ} \mathrm{C}-400^{\circ} \mathrm{C}$ with increments of $50^{\circ} \mathrm{C}$. Subsequently, Vickers micro-hardness HV 0.05 was determined using a LECO LM300AT micro-hardness tester. The powder particles were preliminarily fixed by resin vacuum infiltration and subsequently grinded and polished before 


\section{Hardening and thermal stability of NC AlMg4.8}

testing the core hardness. The given hardness values represent the average of 15 separate measurements. A hardness scatter of $\sim 12 \mathrm{HV}$ and a grain size scatter of $\sim 7 \mathrm{~nm}$ at a grain size of $45 \mathrm{~nm}$ indicate a good homogeneity of the milled material. This proves the reliability of microhardness testing of the coarsened powder particles. The particle size is $\sim 500 \mu \mathrm{m}$ in the asmilled state due to cold welding during milling. Calorimetric studies on the as-milled powder after $8 \mathrm{~h}$ milling time and subsequently annealed powders were carried out by means of a differential scanning calorimeter DSC 204/F1 Phoenix from Netzsch. The powders were sealed in Al pans and investigated at a heating rate of $10 \mathrm{~K} / \mathrm{min}$ in flowing nitrogen atmosphere. Also heating rates of 5 and $20 \mathrm{~K} / \mathrm{min}$ were applied in the as-milled state. The DSC was calibrated for the required particular heating rates before starting the measurement.

Transmission electron microscopy (TEM) was performed on a Philips CM 200 microscope. As the powder particle size increased during milling, grinding and subsequent electrochemical polishing were applied for preparation. Selected area diffraction pattern were taken. The sample area contributing to the diffraction patterns was kept constant at $25.3 \mu \mathrm{m}^{2}$. The quantification of the crystallite size and the dislocation density was done with X-ray diffraction (XRD) experiments. The experiments were performed with a double crystal diffractometer setup, according to Wilkens and Eckert [13], corrected for instrumental broadening. In this case up to five diffraction profiles were recorded for each sample, from the (111) to the (222) reflection. The Multiple Whole Profile (MWP) fit procedure, developed by Ungár et al. [14] and implemented into a software package by Ribárik et al. [15] was used for profile analysis. In this procedure, simulated profiles are fitted to the recorded profiles. This is done simultaneously with ab initio theoretical functions for the strain and size induced profile broadening. As a result values for the median and the variance of a $\log$ normal crystallite size distribution are received. For clarity these values are converted into volume averages according to Hinds [16]. During recent years this method became well established for investigating nanocrystalline and ultrafine grained materials [17]. In Fig. 1 the massive peak broadening due to the nanosized grain structure in the as-milled state is shown. After heat treatment at a temperature of $400{ }^{\circ} \mathrm{C}$ for $3 \mathrm{~h}$, the peak becomes narrower as grain coarsening and dislocation annihilation occurred. These peaks indicate the increase of the average grain size from $73 \mathrm{~nm}$ to $297 \mathrm{~nm}$.

[Insert figure 1 about here]

Fig. 1. Comparison of the peak widths of AlMg4.8 in the as-milled $(8 \mathrm{~h})$ and annealed $\left(400{ }^{\circ} \mathrm{C} 3 \mathrm{~h}\right)$ state obtained by XRD.

\section{Results}

\subsection{Synthesis}

3.1.1 Microstructure and hardness evolution during synthesis. The microstructure in the asatomized state is dendritic. The microstructure of the milled powder was investigated by TEM after $8 \mathrm{~h}$ of milling (Fig. 2). According to XRD analysis the as-milled specimen is a supersaturated fcc solid solution. The TEM bright field image of the powder depicts a grain structure in the range of $50-120 \mathrm{~nm}$. The grain size distribution is homogenous and monomodal and the outlines of the grains are diffuse. The grain size obtained after 8,32 and $50 \mathrm{~h}$ milling time was determined by means of XRD and was found to be 73,45 and $44 \mathrm{~nm}$ respectively (Fig. 3). No information is 


\section{Hüller et al.}

given by XRD investigation about the fraction of large and small angle grain boundaries. The results of these two characterisation techniques are in good agreement, indicating that the area investigated by TEM is representative.

[Insert figure 2 about here]

Fig. 2. TEM bright field image of the as-milled nc AlMg4.8 powder and selected area diffraction pattern.

The micro-hardness increased with the milling time which is shown in Fig. 3. No hardness plateau was reached within the first $50 \mathrm{~h}$ of milling. According to the hardness values, $\mathrm{AlMg} 4.8$ still shows hardening even if a nano-scaled microstructure was adjusted. This result differs strongly from the findings of Koch [18]. In his study $\mathrm{Zn}$ show no steady increase of hardness in the first hours of milling. Nevertheless this strongly depends on the milling parameter and the powder. The rapid decrease in grain size within the first hours of milling and its steady state after prolonged milling is consistent with the findings of Shaw et al. [19]. This implies the fast generation of dislocation networks and the generation of small grains [18]. The misorientation of the grains also increases with increasing milling time [20]. This probably leads to the found increase in hardness.

[Insert figure 3 about here]

Fig. 3. Change of micro-hardness and crystallite size as a function of milling time.

3.1.2 Composition and contamination during synthesis. In order to evaluate the contaminations introduced in the powder by milling, the composition of the as-sprayed powder and as-milled powder after a milling time of $32 \mathrm{~h}$ was investigated (Table 1.). The element iron ( $\mathrm{Fe})$ is the only contamination which was introduced by the milling tools during service. Its content increased from $0.070 \mathrm{wt} \%$ up to $0.078 \mathrm{wt} \%$. Nevertheless, the Fe contamination is still on a very low level.

The other main source of contamination is the absorption of gases as hydrogen $(\mathrm{H})$, nitrogen $(\mathrm{N})$ and oxygen $(\mathrm{O})$ during the milling process. This could also happen if the process is performed in argon atmosphere due to adhering molecules on the particle surfaces. The relevant processes during milling as cold welding, fracturing and deformation generate activated surfaces. This promotes intense diffusion of the $\mathrm{H}, \mathrm{N}$ and $\mathrm{O}$ atoms into the material.

[Insert table 1 about here]

The values determined by hot gas extraction in the as-atomized state and after milling durations of $8 \mathrm{~h}$ and $32 \mathrm{~h}$ are given in Table 2 . The high oxygen content could be justified by the reaction with Aluminium to $\mathrm{Al}_{\mathrm{X}} \mathrm{O}_{\mathrm{Y}}$. The rather slow increase of $\mathrm{H}$ and $\mathrm{N}$ content could be deduced from the lack of reaction with the milled material. Thus, these elements are interstitially solved in the AlMg4.8 lattice. The low contents especially of $\mathrm{H}$ and $\mathrm{N}$ are in good accordance with the low solubility of these elements as found in the phase diagrams [21]. 
Hardening and thermal stability of NC AlMg4.8

[Insert table 2 about here]

\subsection{Thermal stability}

3.2.1 Grain size and hardness evolution. In Fig. 4 the crystallite size and the dislocation density evolution are given in dependence of the annealing temperature. At an annealing time of $3 \mathrm{~h}$ for temperatures larger than $250{ }^{\circ} \mathrm{C}$ the average grain size increased steadily. Concurrently the dislocation density decreased. After annealing at $400{ }^{\circ} \mathrm{C}$ the dislocation density is below $10^{13} \mathrm{~m}^{-2}$, which is the detection limit of the applied XRD based method.

[Insert figure 4 about here]

Fig. 4. Crystallite size and dislocation density evolution in dependence of annealing for $3 \mathrm{~h}$ at different temperatures of $\mathrm{AlMg} 4.8$ preliminary milled for $8 \mathrm{~h}$.

Fig. 5 shows the hardness evolution of the powder milled for $8 \mathrm{~h}$ at different annealing times and temperatures. The plotted points and error bars represent the average value of 15 hardness measurements with the corresponding standard deviation. A slight hardness maximum is found at a temperature of $100{ }^{\circ} \mathrm{C}$ for an annealing time of $3 \mathrm{~h}$ and $100 \mathrm{~h}$. This peak is shifted to around $150{ }^{\circ} \mathrm{C}$ at the shorter annealing time of $0.5 \mathrm{~h}$. The hardness then steadily decreases for all annealing times at higher temperatures at a slowly decreasing slope. As annihilation and polygonisation are time-dependent the hardness at a given temperature above $150{ }^{\circ} \mathrm{C}$ is higher at shorter annealing times.

[Insert figure 5 about here]

Fig. 5. Microhardness of AlMg4.8 powder milled for $8 \mathrm{~h}$ after annealing at different temperatures for $0.5 \mathrm{~h}, 3 \mathrm{~h}$ and $100 \mathrm{~h}$.

3.2.2 DSC measurements. DSC measurements were performed on the as-milled powder $(8 \mathrm{~h})$ and on annealed samples with different heating rates. The curves show qualitatively similar characteristics at different heating rates. Therefore, in Fig. 6 DSC measurements after different annealing temperatures at an annealing time of $3 \mathrm{~h}$ are shown exemplarily, where a heating rate of $10 \mathrm{~K} / \mathrm{min}$ was used.

[Insert figure 6 about here]

Fig. 6. DSC curves for the as-milled and annealed sample at a heating rate of $10 \mathrm{~K} / \mathrm{min}$. 


\section{Hüller et al.}

The calorimetric data on the NC powders in the as-milled state show two pronounced exothermic peaks. A low temperature peak (LT) is found in a temperature range of $100-230{ }^{\circ} \mathrm{C}$. A high temperature peak (HT) starts at $\sim 260{ }^{\circ} \mathrm{C}$ and is more pronounced than the LT-peak. After annealing at $200{ }^{\circ} \mathrm{C}$ the LT-peak disappeared and the height of the HT-peak slightly decreased. After annealing at even higher temperatures up-to $350{ }^{\circ} \mathrm{C}$ the height and the slope of the HT-peak continuously decreased.

As expected the peaks become more pronounced with increasing heating rate and the peak temperatures were shifted to higher values when the heating rate was increased. The respective peak temperatures for all applied heating rates are given in table 3.

[Insert table 3 about here]

3.2.3 Activation energy of grain growth. The DSC measurements presented in Fig. 6 show the two exothermic peaks, designated as low (LT) and high (HT) peak in the as-milled state. The LTpeak refers to the relaxation of thermodynamically non-equilibrium grain boundaries and recovery processes. The HT-peak refers to the excess of residual Gibbs free energy of grain growth processes. In this study grain growth was confirmed by TEM investigation of the samples at $200{ }^{\circ} \mathrm{C}$ and $400{ }^{\circ} \mathrm{C}$. These temperatures are before and after the HT peak respectively. Tschöpe et al. [22] showed for NC Pt that the Gibbs free energy can be estimated as the enthalpy change. The entropy contribution in this regard is negligible small.

In order to evaluate the activation energy of these two processes quantitatively, two different methods were pursued. One is based upon the shift of the DSC peaks caused by the variation of the heating rate also known as Kissinger analysis. The other rests upon the grain size evolution during annealing. Both calculations are given in the Appendix. Table 4 shows the results from the Kissinger analysis from which an activation energy Q of $120-126 \mathrm{~kJ} / \mathrm{mol}$ was obtained for the LT-peak and $201-210 \mathrm{~kJ} / \mathrm{mol}$ for the HT-peak. Table 4 shows that the exponent used in the Kissinger approach has only a minor influence on the results.

[Insert table 4 about here]

With the static grain growth approach an activation energy of $204 \mathrm{~K} / \mathrm{J} / \mathrm{mol}$ was obtained for the HT peak. This value is in the range of the results calculated by the Kissinger analysis and indicates a good agreement between these methods.

3.2.4 Enthalpy release. The area below the exothermic peaks indicates the amount of the enthalpy release. In the following a quantitative approach was pursued to determine the enthalpy release of NC AlMg4.8 based on the DSC plot of the as-milled $(8 \mathrm{~h})$ powder measured at a heating rate of $10 \mathrm{~K} / \mathrm{min}$. The enthalpy releases of the exothermic LT and HT reactions were calculated by integrating the DSC signal. As the used DSC apparatus allows only measurements up to $400{ }^{\circ} \mathrm{C}$ the HT-peak could not be fully recorded. Therefore the area below the peak was extrapolated by integrating the area from the onset of the peak up to the maximum and multiplied by the factor 2 . This assumption of a symmetric DSC peak shape of NC materials was reported by Eckert et al 


\section{Hardening and thermal stability of NC AlMg4.8}

[23]. The heat release of the LT- and HT-peak were calculated to be $39 \mathrm{~J} / \mathrm{mol}$ and $208 \mathrm{~J} / \mathrm{mol}$ respectively.

3.2.5 Hardening in the NC regime and impurity influence. First the impurity effect introduced during the process on the mechanical properties is discussed. The increasing contamination content probably only has a minor influence on the rising hardness with longer milling times. The amount of the Fe content after $32 \mathrm{~h}$ milling is negligible small. Under the precondition that all oxygen atoms reacted with $\mathrm{Al}$, around $180 \mathrm{ppm}$ and $480 \mathrm{ppm} \mathrm{Al}_{2} \mathrm{O}_{3}$ were created in $\mathrm{AlMg} 4.8$ after $8 \mathrm{~h}$ and $32 \mathrm{~h}$ milling time, respectively. Summarizing these results a maximum oxide content of $\sim 0.2$ wt. $\%$ and $\sim 0.5$ wt. $\%$ can be assumed for $8 \mathrm{~h}$ and $32 \mathrm{~h}$ milling. On the other hand the hardness increases from 153 to 212 HV0.05 for powders milled for 8 or 32 hours. Thus the small increase in the second phase content probably only has a minor influence on the mechanical properties.

Therefore, the hardness increase has to be correlated to microstructural changes. Concerning the grain size, a decrease from $73 \mathrm{~nm}$ after $8 \mathrm{~h}$ milling down to $45 \mathrm{~nm}$ after $32 \mathrm{~h}$ and $44 \mathrm{~nm}$ after $50 \mathrm{~h}$ milling was found. The small grain size almost excludes conventional hardening mechanism as complete dislocation pile ups. Nevertheless, full dislocations are necessary for grain refinement. As this happened here up to $32 \mathrm{~h}$ milling time conventional dislocation multiplication mechanisms might still be active. However longer milling up to $50 \mathrm{~h}$ yielded only negligible grain refinement indicating the lower grain size limit of the current alloy. Proceeding hardness increase after milling times $>32 \mathrm{~h}$ might be the result of full or partial dislocation multiplication associated with mechanical twinning [24]. Polygonisation came to an end at the mentioned minimum grain size of $\sim 44 \mathrm{~nm}$.

An estimation concerning the validity of the Hall-Petch relation (1) is given in Fig. 7.

$H_{M}=H_{0}+k \frac{1}{\sqrt{d}}$

Where $\mathrm{H}_{M}$ is the hardness after a specific milling time, $\mathrm{H}_{0}$ is the hardness after long time annealing, $\mathrm{k}$ is the Hall-Petch constant and $\mathrm{d}$ the average grain diameter. $\mathrm{H}_{0}$ was determined after annealing at $530^{\circ} \mathrm{C}$ for $3 \mathrm{~h}$ to be $48 \mathrm{HV} 0.05$.

[Insert figure 7 about here]

Fig. 7. Correlation of grain size and hardness of AlMg4.8 linearised in a Hall-Petch plot after different process routes.

A slope of 0.52 is obtained which stands for the exponent in a Hall-Petch type equation. This verifies the applicability of the Hall-Petch relation down to a grain size of $45 \mathrm{~nm}$. This is consistent with the conclusions in the review of Dao et al. [25]. In this range the hardness increase probably is due to full dislocation pile-ups indicated by the consistence with the linear Hall-Petch curve. At a grain size below $45 \mathrm{~nm}$ the hardness increase proceeds at a higher rate. Even if deformation mechanisms like partial dislocations and twins are active and present in this grain size regime, the hardness increase can not be exclusively dedicated to this phenomenon. A proceeding dispersion of the contamination and even a slight increase in the contamination content with ongoing milling could also influence the hardness increase. 


\section{Hüller et al.}

\section{Discussion}

\subsection{Thermally activated processes}

The gained information about recovery and grain growth reactions confirms the hardness evolution in dependence of the annealing time (Fig. 5). The onsets of the hardness decrease after $3 \mathrm{~h}$ and $100 \mathrm{~h}$ annealing start between $100{ }^{\circ} \mathrm{C}$ and $150{ }^{\circ} \mathrm{C}$. At $0.5 \mathrm{~h}$ annealing time the onset is shifted to higher temperatures above $150{ }^{\circ} \mathrm{C}$. The first exothermic peak (LT) is found in the DSC plot at around $160{ }^{\circ} \mathrm{C}$. This implies that the microstructure is more stable in the DSC tests than in hardness measurement. This finding is comprehensible as the gradual temperature increase displaces the peak to higher temperatures.

The assumption that the LT-peak refers to recovery processes is confirmed by the XRD investigations shown in Fig. 4. The dislocation density strongly decreased during annealing at a temperature around $250{ }^{\circ} \mathrm{C}$ which can be deduced to annihilation, polygonisation and relaxation of non equilibrium grain boundaries. The decrease in heat release and the disappearance of the peak with increasing annealing temperature as shown in Fig. 6 also confirms this assumption. It indicates that the energy stored by the dislocations decreased when a preliminary heat treatment was conducted. As the amount of energy per dislocation is estimated to be constant, this is originated by a decreasing number of dislocations.

The HT-peak which is supposed to refer to grain growth and recovery processes along high angle grain boundaries shows a decrease in the size and also a slight decrease in the slope if the asmilled and the annealed state is compared. This means that a small amount of energy was released during preliminary annealing setting the grain boundaries in a state of higher thermodynamic stability. These changes in the character of the non-equilibrium grain boundaries in the as-milled state are mainly attributed to reorganisation and relaxation processes. The slope as well as the height of the peak stayed constant until an annealing temperature of around $250{ }^{\circ} \mathrm{C}$. Therefore only slight grain coarsening occurred in the temperature range $<250{ }^{\circ} \mathrm{C}$, comparing the grain size of $73 \mathrm{~nm}$ in the as-milled state and $146 \mathrm{~nm}$ after $3 \mathrm{~h}$ annealing at $250{ }^{\circ} \mathrm{C}$ (Fig. 4). According to Fig. 5, the slope of the hardness decrease related to recovery is higher than that related to grain growth. Thus, if the dislocation density is strongly reduced by annihilation, the hardness could be much lower even if the grain size has not varied significantly. This underlines the meaning of dislocations for $\mathrm{NC}$ materials and points out that the recovery rate is an important factor regarding the mechanical properties. The high dislocation density of the AlMg4.8 powder milled for $8 \mathrm{~h}$ indicates that the grain refinement has not been finished yet. This is confirmed as the grain size decreased with longer milling time as already mentioned. Even after $32 \mathrm{~h}$ milling the final microstructure was not obtained. This value is given by the competition between mechanically induced disordering and thermally activated reordering processes.

\subsection{Effect of the grain size on the growth exponent}

Summarizing the results concerning the activation energy for the temperature range above $260{ }^{\circ} \mathrm{C}$, this temperature refers to the onset temperature of the HT-peak in the as-milled state. With the Kissinger approach an activation energy of $201-210 \mathrm{~kJ} / \mathrm{mol}$, whereas the static grain growth analysis resulted an activation energy of $204 \mathrm{~kJ} / \mathrm{mol}$. The very good consistency of these results also confirms the accuracy of the used exponent $n=0.08$ in the analysis of static grain growth taken from literature [26]. The activation energy measured by Wang et al. [27] on non- 


\section{Hardening and thermal stability of NC AlMg4.8}

recrystallised UFG AlMg3 in the temperature range below $548 \mathrm{~K}$ prepared by ECAP was reported to be only $30 \mathrm{~kJ} / \mathrm{mol}$. This value is significantly lower than the result of the present study. The massive deviation can be attributed to the exponent $n$, where 0.5 is used for static grain growth in conventional materials as derived from Burke [28]. However, the validity of this equation is focused on conventional coarse grained materials. The exponent $\mathrm{n}$ has to be adapted to UFG and NC materials. The value $n=0.08$ adopted in this study was empirically derived and mainly depends on the grain size and not on the material [30]. For clarification, if $n=0.5$ is used in the present study, an activation energy of $\sim 36 \mathrm{~kJ} / \mathrm{mol}$ would be derived. This is the same order of magnitude of the result of Wang et al. [27]. The slightly higher activation energy could be explained by the higher $\mathrm{Mg}$ content and a smaller initial grain size.

\subsection{Effect of the alloying element Mg on the activation energy}

The activation energy for grain boundary migration in a solid solution is in the range of selfdiffusion or diffusion of solutes [29]. Activation energies of $144.4 \mathrm{~kJ} / \mathrm{mol}$ for lattice self diffusion and $86 \mathrm{~kJ} / \mathrm{mol}$ for grain boundary diffusion in $\mathrm{Al}$ are reported in literature [30]. The lattice self diffusion is therefore $\sim 30 \%$ lower than the calculated activation energy of $201-210 \mathrm{~kJ} / \mathrm{mol}$. This indicates that the activation energy is also influenced by other effects. The retardant force due to solute drag or Zener pinning is supposed to be the fundamental mechanism. Due to the high interfacial area in NC materials the particles or solute atoms can be dispersed finely and impede grain boundary motion. This grain size dependence of the pinning forces was first discussed by Michels et al. [31]. They adapted the assumption given by Burke [28] to NC materials. For the studied alloy $\mathrm{AlMg} 4.8$ second phase particles as $\mathrm{Mg}_{17} \mathrm{Al}_{12}$ precipitates and $\mathrm{Al}_{2} \mathrm{O}_{3}$ are supposed to be not as significant for microstructural stabilisation due to their low fraction as solute atoms. Solute $\mathrm{Mg}$ atoms and vacancies should have a much higher effect due to a higher quantity and a more homogenous dispersion.

May et al. [32] obtained an activation energy of $70-90 \mathrm{~kJ} / \mathrm{mol}$ in a similar temperature range of $293-473 \mathrm{~K}$ by strain rate jump tests on UFG A199.5. The reason for the $\sim 35 \%$ lower value compared to the data presented here could be explained by the effect of the alloying element $\mathrm{Mg}$. The activation energy for $\mathrm{Mg}$ diffusion in $\mathrm{Al}$ was found to be $120.5 \mathrm{~kJ} / \mathrm{mol}$ [33]. Atodiresei et al. [34] obtained the activation energy for $\mathrm{Mg}$ diffusion in $\mathrm{AlMg} 4$ by mechanical spectroscopy in a comparable temperature range to be $\sim 121.2 \mathrm{~kJ} / \mathrm{mol}$. This means that dislocation movement is controlled by $\mathrm{Mg}$ diffusion. The process is also known as dynamic strain aging or Portevin-Le Châtelier effect (PLC). The hardness evolution confirms this hypothesis as the hardness increased at around $100^{\circ} \mathrm{C}-150^{\circ} \mathrm{C}$ at an annealing time of $3 \mathrm{~h}$ and $100 \mathrm{~h}$ and at $150{ }^{\circ} \mathrm{C}$ for $0.5 \mathrm{~h}$. During annealing, $\mathrm{Mg}$ atoms can diffuse to dislocations during the process of solute redistribution and are trapped in the dilatation zone. Consequently the resistance to dislocation motion increased.

\subsection{Energy stored in NC AlMg4.8}

The obtained values of $39 \mathrm{~J} / \mathrm{mol}$ and $208 \mathrm{~J} / \mathrm{mol}$ for recovery and grain growth respectively are very high. As discussed in the chapter concerning strain hardening, the low stacking fault energy could be an important precondition for the storage of a large amount of energy inside the material in terms of dislocations.

This assumption was verified in the following by a theoretical approach, calculating the energy which is stored in the dislocation. Herein the stored energy due to dislocations is assumed to be 


\section{Hüller et al.}

proportional to the dislocation density. For this approach the dislocation density of $\rho=1.58 * 10^{16} \mathrm{~m}^{-2}$ shown in Fig 4 was applied in equation 2 .

$E_{D}=\rho E_{D i s}$

Where $E_{D}$ is the total strain energy of dislocations and $E_{\text {Dis }}$ the strain energy associated with unit length of dislocation line. $\mathrm{E}_{\mathrm{Dis}}$ is calculated according equation 3 [35].

$E_{D i s}=\frac{G b^{2}\left(\frac{1-v}{2}\right)}{4 \pi(1-v)} \ln \left(\frac{\alpha R}{2 b}\right)$

Where $G$ is the shear modulus, $b$ the Burgers vector, $v$ the Poisson ratio, $R$ is the separation between screw and edge dislocations and $\alpha$ is the core unity factor. Adopting $\mathrm{G}=25.4 \mathrm{GPa}$, $\mathrm{b}=0.286 \mathrm{~nm}, v=0.3, \rho=1.58 * 10^{16} \mathrm{~m}^{-2}, \mathrm{R}=\rho^{-0.5}$ and $\alpha=1, \mathrm{E}_{\mathrm{D}}$ was found to be $\sim 213 \mathrm{~J} / \mathrm{mol}$. Considering the error due to approximations in the applied equations this finding is in good agreement with the heat release measured by DSC peak integration (Tab. 4). Consequently the emitted energy obtained from the DSC measurements can be completely attributed to dislocation recovery processes. The much higher energies detected by DSC measurements reported by Zhou et al [29] for a NC Al-Mg alloy can not be confirmed. Therein the gap between the DSC results and the calculated energy stored by dislocations were explained by other sources like twinning and non-equilibrium grain boundaries. The influence of these mechanisms concerning the stored energy seems not to be dominant for the investigated $\mathrm{NC} A l M g 4.8$. The different milling processes can be an explanation for this, as cryomilling in an attritor was applied. This process is known to be more effective in nanostructuring as the energy density of the apparatus is higher and recovery is suppressed due to the low temperature.

Molecular dynamic simulations on NC materials predicted that samples consisting of high angle grain boundaries (HAGB) have most of their excess energy in the grain boundaries [36]. Those consisting of low angle grain boundaries (LAGB) store the energy in the interior as elastic distortion. The small LT-peak therefore belongs to the energy stored inside the grains or inside LAGB. The enthalpy release requires lower temperatures and activation energies. The release of the energy stored inside the grain boundaries of HAGB samples needed higher activation energy. This is due to their metastable state which is generated by forming grains with high misorientation out of the dislocation networks. Solute atomes as $\mathrm{Mg}$ promote this stability. The existence of the LT-peak indicates that the minimum grain size has not been reached yet after $8 \mathrm{~h}$ milling as there are still dislocations and subgrains in the interior. This finding also explains the validity of the Hall-Petch equation as dislocation pile-ups can still occur in this condition. This assumption is confirmed when the DSC curves of AlMg4.8 milled for $8 \mathrm{~h}$ and $32 \mathrm{~h}$ are compared. Due to the longer milling time the grain size decreased from $73 \mathrm{~nm}$ to $52 \mathrm{~nm}$. Concurrently the energy in the grain interior decreased and is located mostly in the HAGBs. Consequently the DSC curve for the milling time of $32 \mathrm{~h}$ did not show a pronounced LT-peak. This is also consistent with the assumption made with regard to the hardening. It was supposed that when the minimum grain size is reached full dislocation multiplication come to an end. Therefore no recovery processes in terms of annihilation and polygonisation of dislocations can be detected by DSC.

\subsection{Validation of the Hall-Petch relation in the nanocrystalline regime}

The results indicated that the Hall-Petch relation is valid down to the minimum grain size of $\sim 44 \mathrm{~nm}$ as the exponent of the corresponding equation was calculated to be 0.52 . The constant $\mathrm{k}$ 


\section{Hardening and thermal stability of NC AlMg4.8}

of the Hall-Petch relation was also calculated. This result fits well with the linear function of $\mathrm{k}$ vs. Mg content shown in Fig. 8.

[Insert figure 8 about here]

Fig. 8. Hall Petch constant $\mathrm{k}$ depends on the Mg content; $\mathrm{k}$ value of $4.8 \mathrm{wt} \%$ was calculated in the present work while the other results are reported in literature [37-39] .

The lower grain size limit of Al-Mg alloys is influenced by the stacking fault energy. Mohamed [40] found a correlation for ball milled material which has been confirmed later for other NC materials prepared by high pressure torsion [41]. It is known from literature that an increasing content of $\mathrm{Mg}$ strongly decreases the stacking fault energy of Aluminium. The recovery rate is significantly lower as cross slipping of dislocations is more difficult for metals with lower stacking fault energy due to the higher width of the stacking fault ribbon. This results in a higher level of equilibrium concerning the dislocation density at a given temperature. According to the Hall-Petch equation hardness is influenced by the grain size " $d$ " and the parameter " $k$ ". The latter seems to depend on the equilibrium of the dislocation density which explains the observed correlation between the $\mathrm{Mg}$ content in $\mathrm{Al}$ and the parameter $\mathrm{k}$. Therefore the lower grain size limit of $44 \mathrm{~nm}$ determined here for AlMg4.8 is lower than that of pure Aluminium [42/43].

Milling after the lower grain size limit is reached yielded further hardening and could not be explained by the Hall-Petch relationship. The description of the hardness evolution in this regime needs further investigation. This concerns also new deformation mechanisms as partial dislocation emission and absorption by grain boundaries. These mechanisms were originally predicted using molecular dynamic simulations by Yamakov et al. [44] and experimentally first observed by Chen et al. [45]. The mentioned lower stacking fault energy due to $\mathrm{Mg}$ also promotes the generation of partial dislocations and twins. Especially in the state where conventional dislocation multiplication already came to an end these mechanisms might be an explanation for the proceeding hardening at a stable grain size. No inverse Hall-Petch effect was found.

\section{Conclusion}

- AlMg4.8 was investigated concerning the correlation of grain size and hardness down to the nanometer regime. The hardness evolution was found to be consistent with the Hall-Petch relation down to a grain size of $\sim 45 \mathrm{~nm}$. Prolonged milling has no influence on further grain refinement. The influences of ball-milling related impurities were quantified. Even if their amount is rather small, an effect on the hardening at the minimum grain size can not be neglected. Nevertheless deformation mechanisms which are not common in conventional grained aluminium alloys as partial dislocations and twins could be active too.

- Two peaks were found in DSC measurements on as-milled and annealded samples. The activation energies Q of the thermal activated processes were derived by means of DSC analysis. The activation energy for the low temperature recovery peak was found to be $123 \mathrm{~kJ} / \mathrm{mol}$. A similar value of $121 \mathrm{~kJ} / \mathrm{mol}$ was reported in literature for $\mathrm{Mg}$ diffusion in $\mathrm{Al}$. Recovery seems to be controlled by $\mathrm{Mg}$ diffusion. As the investigated specimen has not reached the minimum grain size after $8 \mathrm{~h}$ milling, conventional dislocation mediated mechanisms still are active, which are necessary for further grain refinement. The activation energy for recovery confirms this 


\section{Hüller et al.}

assumption. For grain boundary movement the average activation enery was calculated via static grain growth and Kissinger analysis to be $\sim 205 \mathrm{~kJ} / \mathrm{mol}$. For Al self diffusion Q is $144.4 \mathrm{KJ} / \mathrm{mol}$ which is $\sim 40 \%$ lower than the calculated values. This increase of activation energy for grain growth is explained by the large interfacial area in the material enabling effective pinning by solute atoms and vacancies. This also explains the lower thermal stability of pure Al.

- Enthalpy release $\Delta \mathrm{H}$ during calorimetry was found to be $39 \mathrm{~J} / \mathrm{mol}$ and $208 \mathrm{~J} / \mathrm{mol}$ for recovery and grain growth. The energy $\Delta \mathrm{H}$ stored by the dislocations was calculated to be $\sim 213 \mathrm{~J} / \mathrm{mol}$ using the measured dislocation density. Considering the approximations for the peak integration and the theoretical calculation a good consistency is found. The enthalpy release of the LT and HT-peak was attributed to the grain interior and to high angle grain boundaries respectively. This is consistent with the results of molecular dynamic simulations.

\section{Appendix A: Calculation of the activation energy}

Activation energy via Kissinger analysis. The activation energies of recovery and recrystallisation were determined via DSC measurements at different heating rates according to the Kissinger analysis [48]. The DSC peak positions (Fig. 6) in combination with the corresponding heating rate give information about the activation energy of the thermal activated processes. Using the following equation the activation energy $Q$ of the current processes could be calculated.

$\ln (\alpha)=-\frac{Q}{k_{B} T_{P}}+C$

Here $\mathrm{k}_{\mathrm{B}}$ is the Boltzmann constant and $\mathrm{C}$ is an integration constant. $\alpha$ is a function of the peak temperature $\mathrm{TP}$ and the applied heating rate $\mathrm{L}$.

$\alpha=\mathrm{L} / \mathrm{Tn} \quad$ (A 2)

Kissinger [46] and Chen et al. [47] assumed different exponents in this equation for $\alpha$. The values for the LT and HT-peaks at each heating rate were put in a Kissinger plot (Fig. 9). Based on equation (A 1) and the given equations for $\alpha$ the $\mathrm{Q}$ values could be calculated on the basis of the slopes of the linear curves which are shown in the Kissinger plot.

[Insert figure 9 about here]

Fig. 9. Kissinger plot indicating the activation energy for grain growth.

Activation energy via static grain growth. The relationship between the average grain size and the annealing time for static grain growth could be described in the form given in equation A 3 [28].

$d^{\frac{1}{n}}-d_{0}^{\frac{1}{n}}=c t$

Where $d$ is the grain size after annealing, $d_{0}$ is the initial grain size and $t$ is the time. The exponent $\mathrm{n} \sim 0.08$ was used by Zhou et al. [26] for ball milled $\mathrm{NC} \mathrm{Al}$ for the temperature range $<450^{\circ} \mathrm{C}$. It was generated by applying a nonlinear, general fitting routine to the curve of the grain size and 


\section{Hardening and thermal stability of NC AlMg4.8}

time data. $\mathrm{C}$ is a temperature-dependent constant which could be expressed by an Arrhenius type of equation in the form of:

$c=A e^{(-Q / R T)} \quad(\mathrm{A} 4)$

Where $\mathrm{Q}$ is the activation energy for grain growth, $\mathrm{R}$ the gas constant and $\mathrm{T}$ is the isothermal annealing temperature. The activation energy $Q$ can be determined from the linear plot of $\ln (\mathrm{c})$ and 1/T as shown in Fig. 10.

[Insert figure 10 about here]

Fig. 10. Arrhenius plot of rate constant values obtained by the growth results.

\section{References}

[1] H. Gleiter, Prog. Mater. Sci. 33 (1989) 223-315.

[2] F. Liu, Z. Chen, W. Yang, C.L. Yang, H.F. Wang, Mater. Sci. Eng. A 1 (2007) 13-17.

[3] A. Kumpmann, B. Gunther, H.D. Kunze, Mater. Sci. Eng. A 168 (1993) 165-169.

[4] Y. Estrin, G. Gottstein, L.S. Shvindlerman, Scripta. Mater. 41 (1999) 385-390.

[5] C. Suryanarayana, Prog. Mater. Sci. 46 (2001) 1-184.

[6] E.O. Hall, Proc. Phys. Soc. London B 64 (1951) 747-753.

[7] N.J. Petch, J Iron Steel Inst. 174 (1953) 25-28.

[8] G.J. Fan, G.Y. Wang, H. Choo, P.K. Liaw; Y.S. Park, B.Q. Han, E.J. Lavernia, Scripta Mater. 52 (2005) 929-933.

[9] PP. Chattopadhyay, S.K. Pabi, I. Manna, Z. Metall. 91 (2000) 1049-1052.

[10] R.A. Masamura, M.P. Hazzledine, C.S. Pande, Acta. Mater. 46 (1998) 4527-4537.

[11] K.A. Padmanabhan, G.P. Dinda, H. Hahn, H. Gleiter, Mater. Sci. Eng. A452 (2007) 462-468.

[12] K.M. Youssef, R.O. Scattergood, K. Murty, J.A. Horton, C.C. Koch, Appl. Phys. Lett. 87 (2005) 091904.

[13] M. Wilkens, K.Z. Eckert, Z.f. Naturf. 19a (1964) 459:470.

[14] T. Ungár, I. Dragomir, Á Ribarik, A. Borbély, J. Appl. Cryst. 34 (2001) 298-310.

[15] G. Ribárik, T. Ungár, J. Gubicza, J: Appl. Cryst. 34 (2001) 669-676.

[16] W.C. Hinds, Aerosol Technology: Wiley, New York, 1982.

[17] J. Gubicza, L. Balogh, R.J. Hellmig, Y. Estrin, T. Ungár, Mater. Sci. Eng. A 400 (2005) 334338.

[18] C.C. Koch, Rev. Adv. Mater. Sci. 5 (2003) 91-99.

[19] L. Shaw, M. Zawrah, J. Villegas, H. Luo, D. Miracle, Metall. Mater. Trans. A 34 (2003) 159170.

[20] H.J. Fecht, E. Hellstern, Z. Fu, W.L. Johnson, Metall. Trans. A 21 (1990) 2333

[21] T.B. Massalski, Binary Alloy Phase Diagrams, Materials Park (OH): ASM International, 1990

[22] A. Tschöpe, R. Birringer, Acta Metall. 41(1993) 2791-2796.

[23] J. Eckert, J.C. Holzer, C.E. Krill III, W.L. Johnson, Mater. Sci. Forum 88-90 (1992) 505-512.

[24] L. Manping, H.J. Roven, Y. Yu, Int. J. Mater. Res. 98 (2007) 3, 184-190.

[25] M. Dao, L. Lu, R.J. Asaro, J.T.M. De Hosson, E. Ma, Acta Mater. 55 (2007) 4041-4065.

[26] F. Zhou, J. Lee, S. Dallek, E.J. Lavernia, J. Mater. Res. 16 (2001) 3451-3458.

[27] J. Wang, Y. Iwahashi, Z. Horita, M. Furukawa, M. Nemoto, R.Z. Valiev, T.G. Langdon, Acta Mater. 44 (1996):2973-2982. 
M. Hüller et al.

[28] J.E. Burke, Trans. Metall. Soc. AIME 180 (1949) 73-91.

[29] F. Zhou, X.Z. Liao, X.T. Zhu, S. Dallek, E.J. Lavernia, Acta Mater. 51 (2003) 2777-2791.

[30] E.A. Brandes, G.B. Brook: Smithells Metals Reference Book, 7th ed., The Bath Press, Bath, 1999.

[31] A. Michels, C.E. Krill, H. Ehrhardt, R. Birringer, D.T. Wu, Acta Mater. 47 (1999) 21432152.

[32] J. May, H.W. Höppel, M. Göken. Scripta Mater. 53 (2005) 189-194.

[33] Y. Du, Y.A. Chang, B. Huang, W. Gong, Z. Jin, H. Xu, Z. Yuan, Y. Liu, Y. He, F.Y. Xie, Mater. Sci. Eng. A 363 (2003) 140-151.

[34] M. Atodiresei, G. Gremaud, R. Schaller, Mater. Sci. Eng. A442 (2006) 160-164.

[35] J.P. Hirth, J. Lothe, Theory of dislocations, 2nd ed. New York, NY: Wiley, 1982.

[36] J.R. Weertman, D. Farkas, K. Hemker, H. Kung, M. Mayo, R. Mitra, H. Van Swygenhoven, MRS Bulletin 2 (1999) 44-49.

[37] R. Armstrong, I. Codd, R.M. Douthwaite, N.J. Petch, Phil. Mag. 7 (1962) 45-58.

[38] A.W. Thompson, W.A. Backofen, Acta Metall. 19 (1971) 597-606.

[39] J. May, M. Dinkel, D. Amberger, H.W. Höppel, M. Göken, Metall Mater Trans. A, to appear in 2007.

[40] F.A. Mohamed, Acta Mater. 51 (2003) 4107-41019.

[41] Y.H. Zhao, Y.T. Zhu, X.Z. Liao, Z. Horita, T.G. Langdon, Mater. Sci. Eng. A 463 (2006) 2226.

[42] H.M. Tensi, W. Pless, H.Z. Borchers, Z. Metallkde. 63 (1972) 184-187.

[43] T.C. Schulthess, P.E.A. Turchi, A. Gonis, T.G. Nieh, Acta Mater. 46 (1998) 2215-2221.

[44] V. Yamakov, D. Wolf, S.R. Phillpot, A.K. Mukherjee, H. Gleiter, Nature Mater. 1 (2002) 4549.

[45] M. Chen, E. Ma, K.J. Hemker, H. Sheng, Y. Wang, X. Cheng, Science 300 (2003) 12751277.

[46] H.E. Kissinger, Anal. Chem. 29 (1957) 1702-1706.

[47] L.C. Chen, F.J. Spaegen. J. Appl. Phys. 69 (1991) 679-688.

Figure Caption

Figure 1. Comparison of the peak widths of AlMg4.8 in the as-milled $(8 \mathrm{~h})$ and annealed $\left(400{ }^{\circ} \mathrm{C} / 3 \mathrm{~h}\right)$ state obtained by XRD

Figure 2. TEM bright field image of the as-milled nc AlMg4.8 powder and selected area diffraction pattern

Figure 3. Change of micro-hardness and crystallite size as a function of milling time

Figure 4. Crystallite size and dislocation density evolution in dependence of annealing for $3 \mathrm{~h}$ at different temperatures of AlMg4.8 preliminary milled for $8 \mathrm{~h}$

Figure 5. Hardness of AlMg4.8 powder milled for $8 \mathrm{~h}$ after annealing at different temperatures for $0.5 \mathrm{~h}, 3 \mathrm{~h}$ and $100 \mathrm{~h}$ Figure 6. DSC curves for the as-milled and annealed samples at a heating rate of $10 \mathrm{~K} / \mathrm{min}$

Figure 7. Correlation of grain size and hardness of AlMg4.8 linearised in a Hall-Petch plot after different process routes

Figure 8. Hall Petch constant $\mathrm{k}$ depends on the $\mathrm{Mg}$ content; $\mathrm{k}$ value of $4.8 \mathrm{wt} \%$ was calculated in the present work while the other results are reported in literature [37-39].

Figure 9. Kissinger plot indicating the activation energy for grain growth

Figure 10. Arrhenius plot of rate constant values obtained by the growth results 


\section{Hardening and thermal stability of NC AlMg4.8}

\section{Table Caption}

Table 1. Powder composition in the as-sprayed state and as-milled state after a milling time of $32 \mathrm{~h}$

Table 2. Content of the elements $\mathrm{H}, \mathrm{N}$ and $\mathrm{O}$ in the powder in the as-sprayed state and after $8 \mathrm{~h}$ and $32 \mathrm{~h}$ milling Table 3. DSC peak temperatures in dependence of the heating rate

Table 4. Activation energies for the exothermic reactions designated by LT-peak and HT-peak of AlMg4.8 milled for $8 \mathrm{~h}$ 


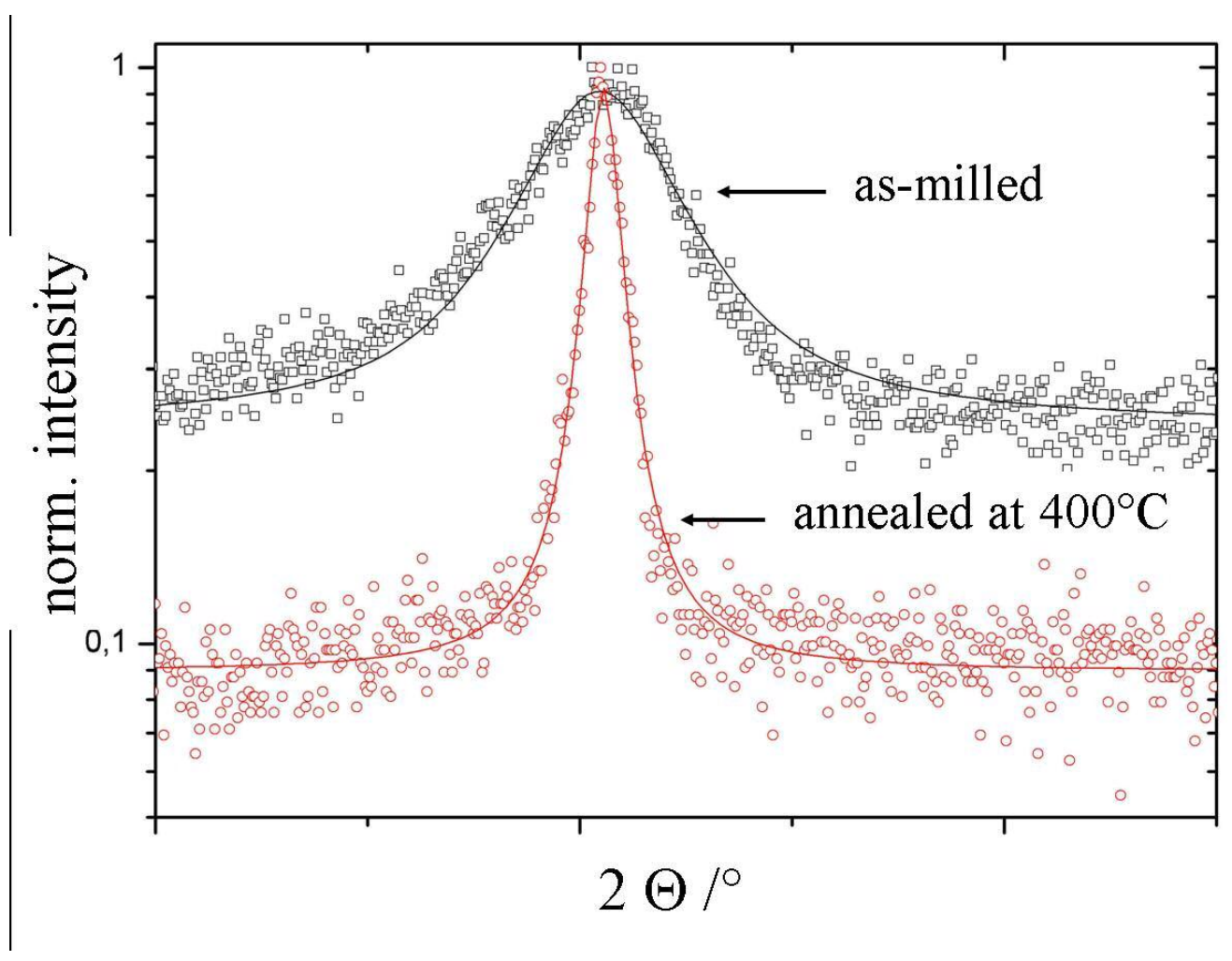

$200 \times 154 m m(150 \times 150$ DPI $)$ 


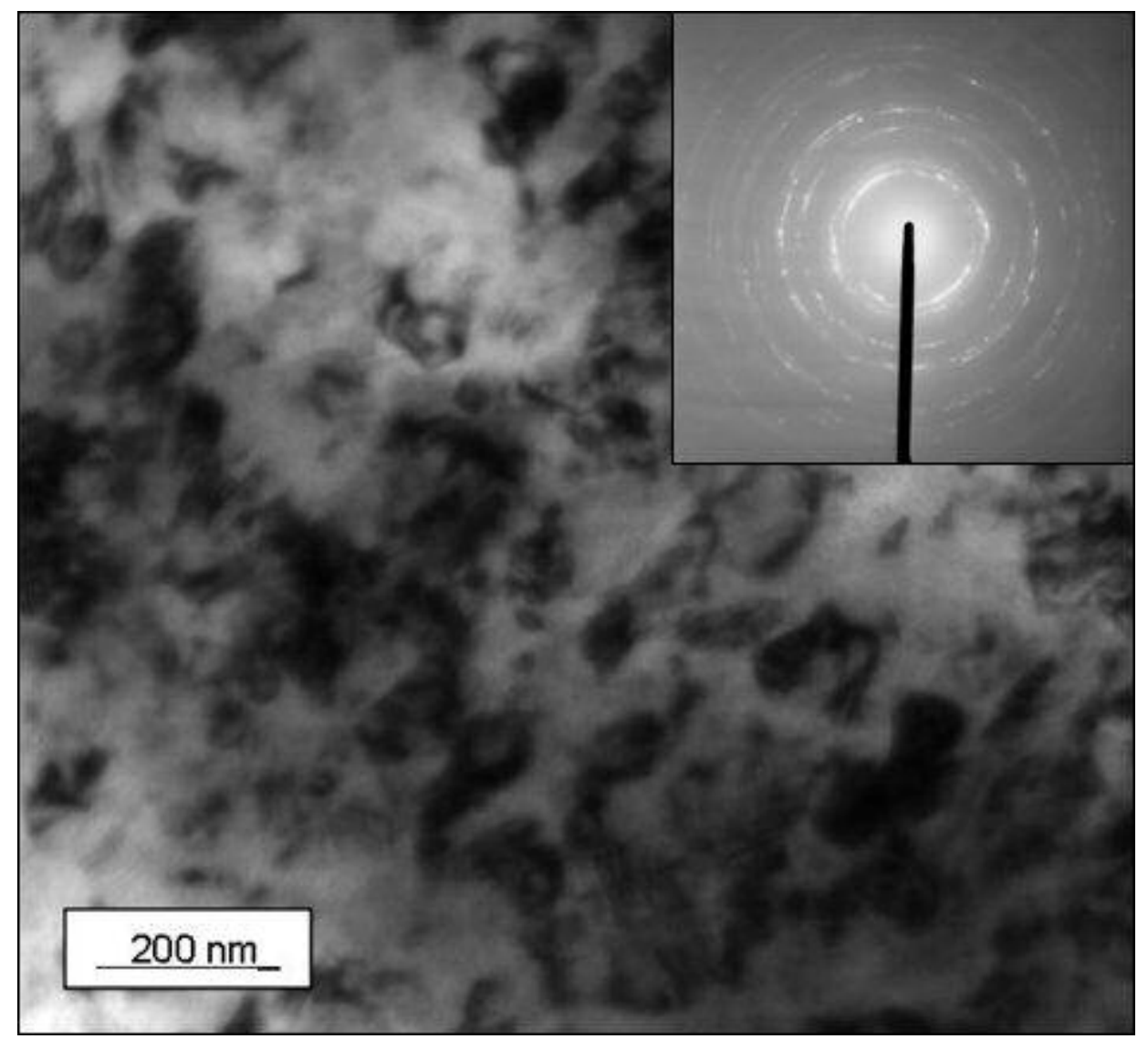

TEM bright field image of the as-milled nc AIMg4.8 powder and selected area diffraction pattern

$165 \times 152 \mathrm{~mm}(72 \times 72 \mathrm{DPI})$ 


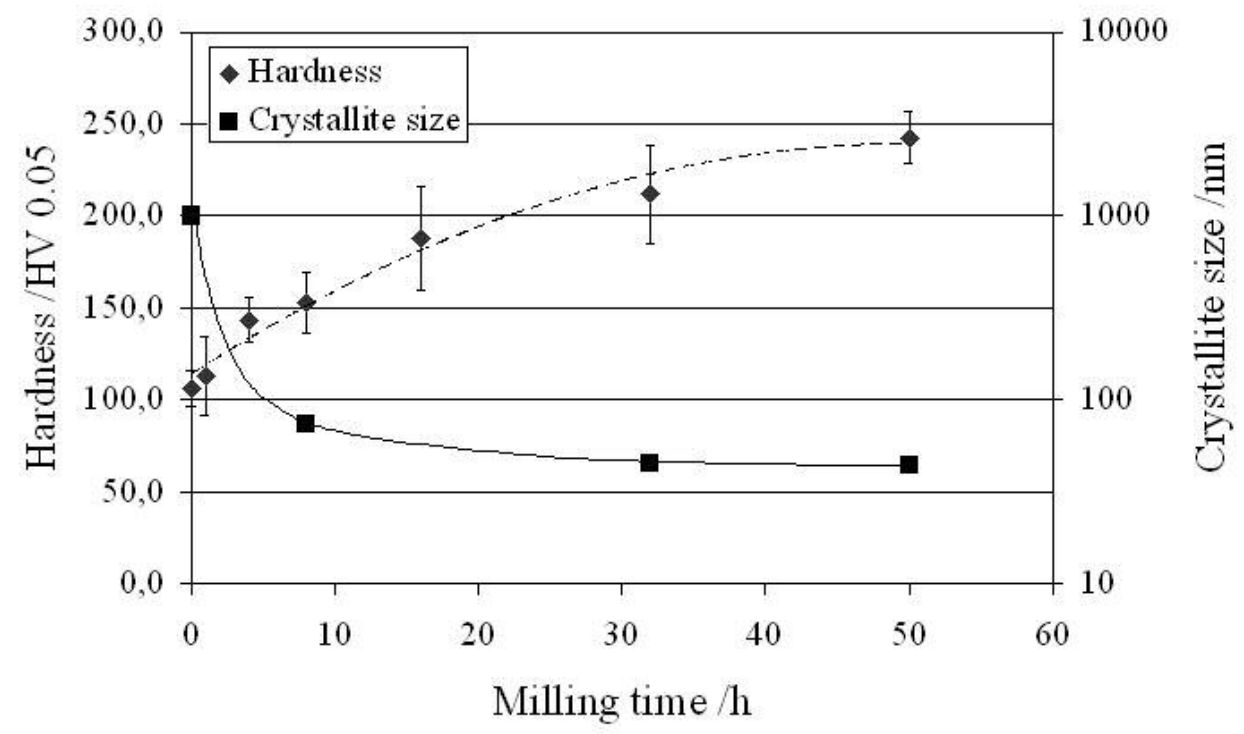

Change of micro-hardness and crystallite size as a function of milling time. $184 \times 114 \mathrm{~mm}(100 \times 100 \mathrm{DPI})$ 


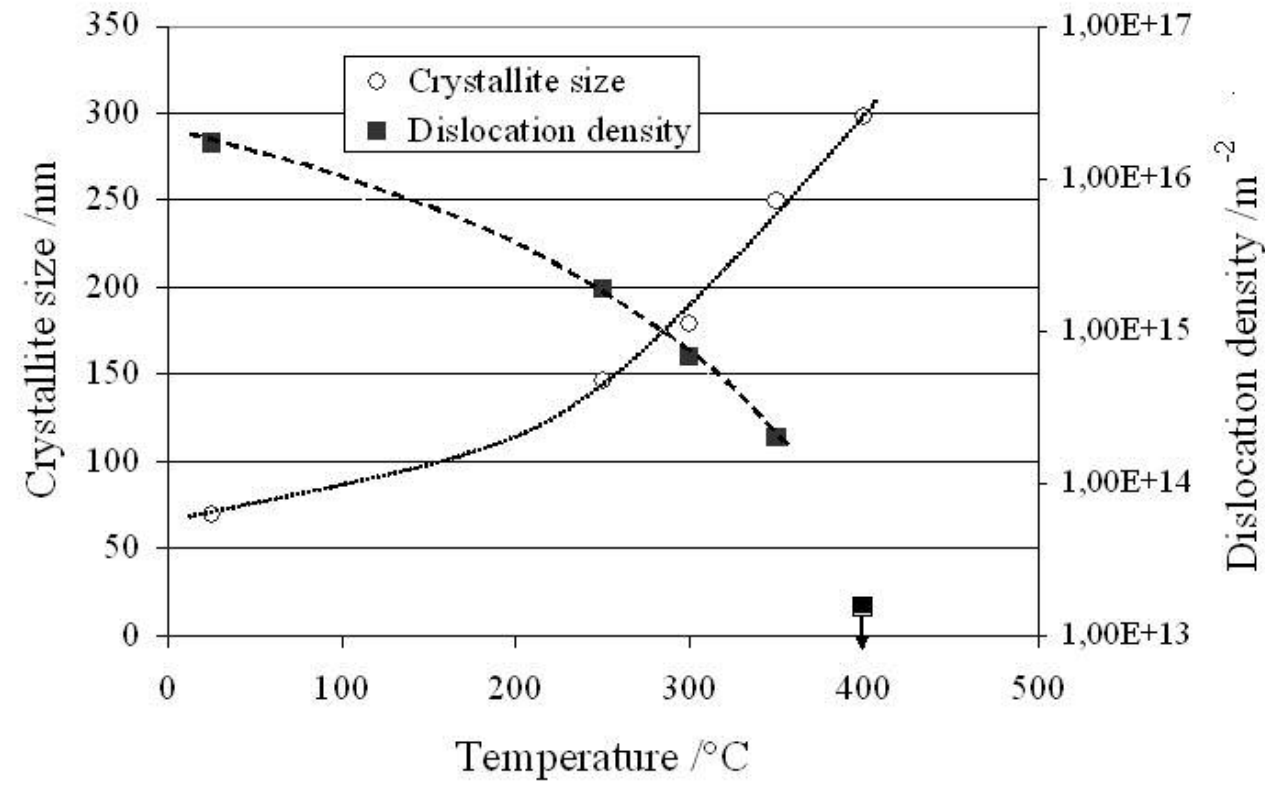

Crystallite size and dislocation density evolution in dependence of annealing for $\mathbf{3} \mathbf{~}$ at different temperatures of AlMg4.8 preliminary milled for $8 \mathrm{~h}$. $180 \times 114 \mathrm{~mm}(100 \times 100 \mathrm{DPI})$ 


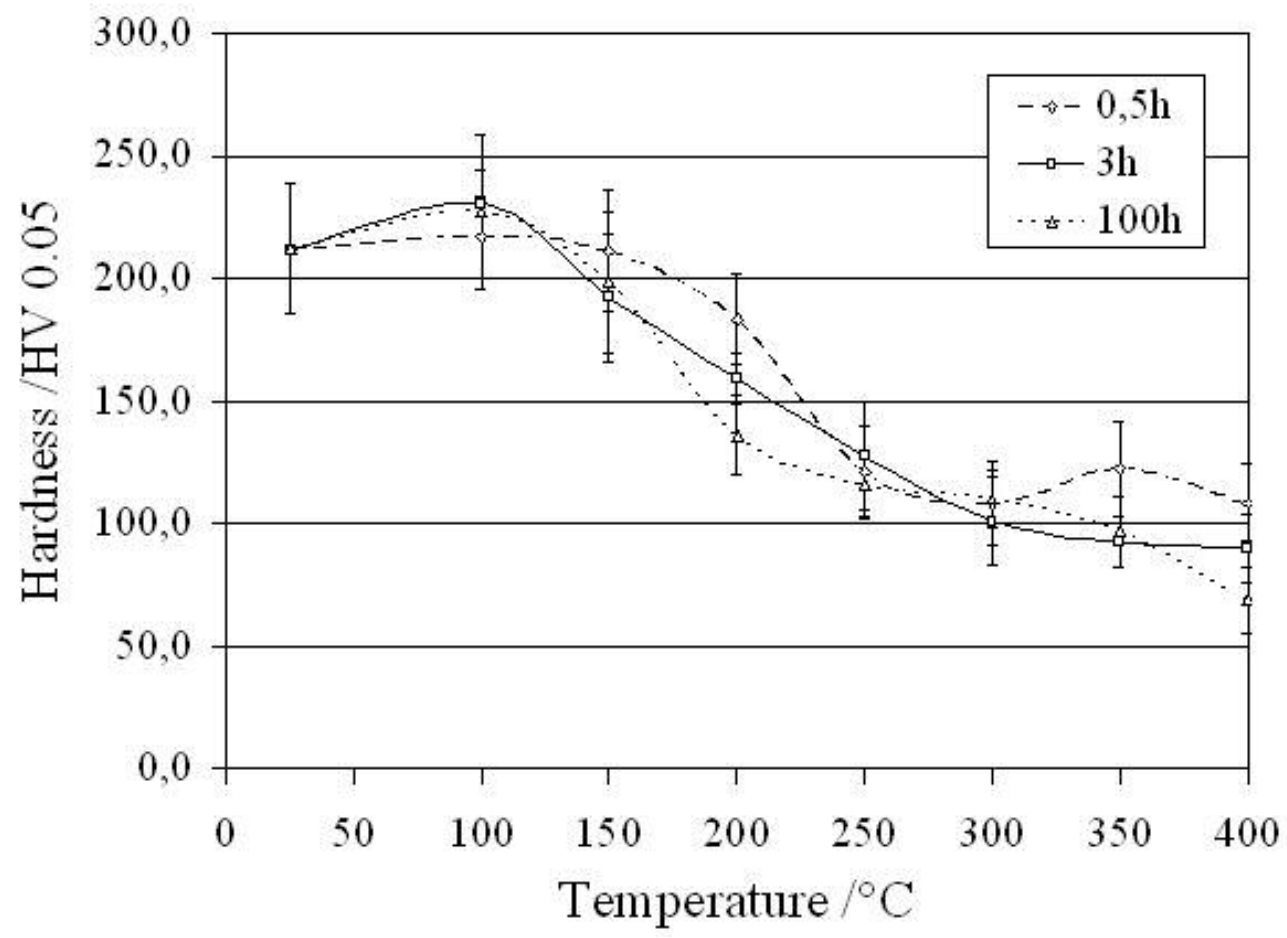

Microhardness of AlMg4.8 powder milled for $8 \mathrm{~h}$ after annealing at different temperatures for $0.5 \mathrm{~h}, 3 \mathrm{~h}$ and $100 \mathrm{~h}$.

$149 \times 109 \mathrm{~mm}(100 \times 100 \mathrm{DPI})$ 


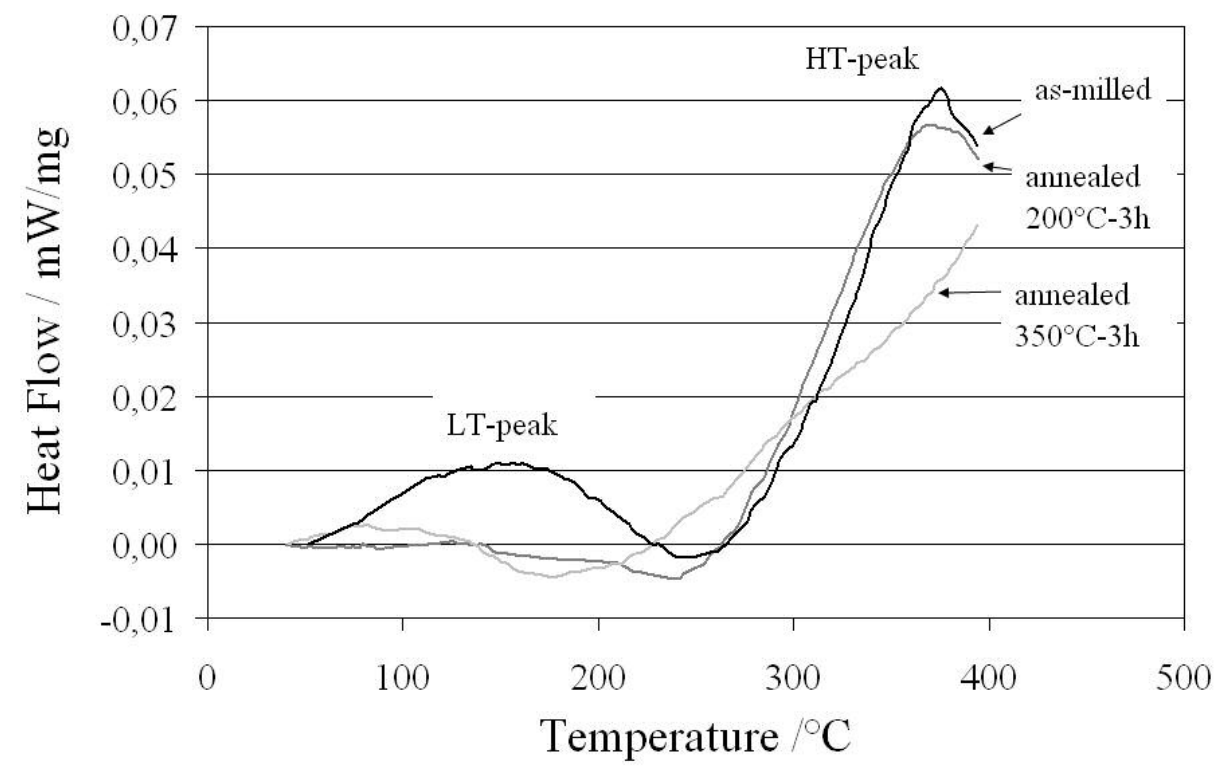

DSC curves for the as-milled and annealed samples at a heating rate of $10 \mathrm{~K} / \mathrm{min}$ 


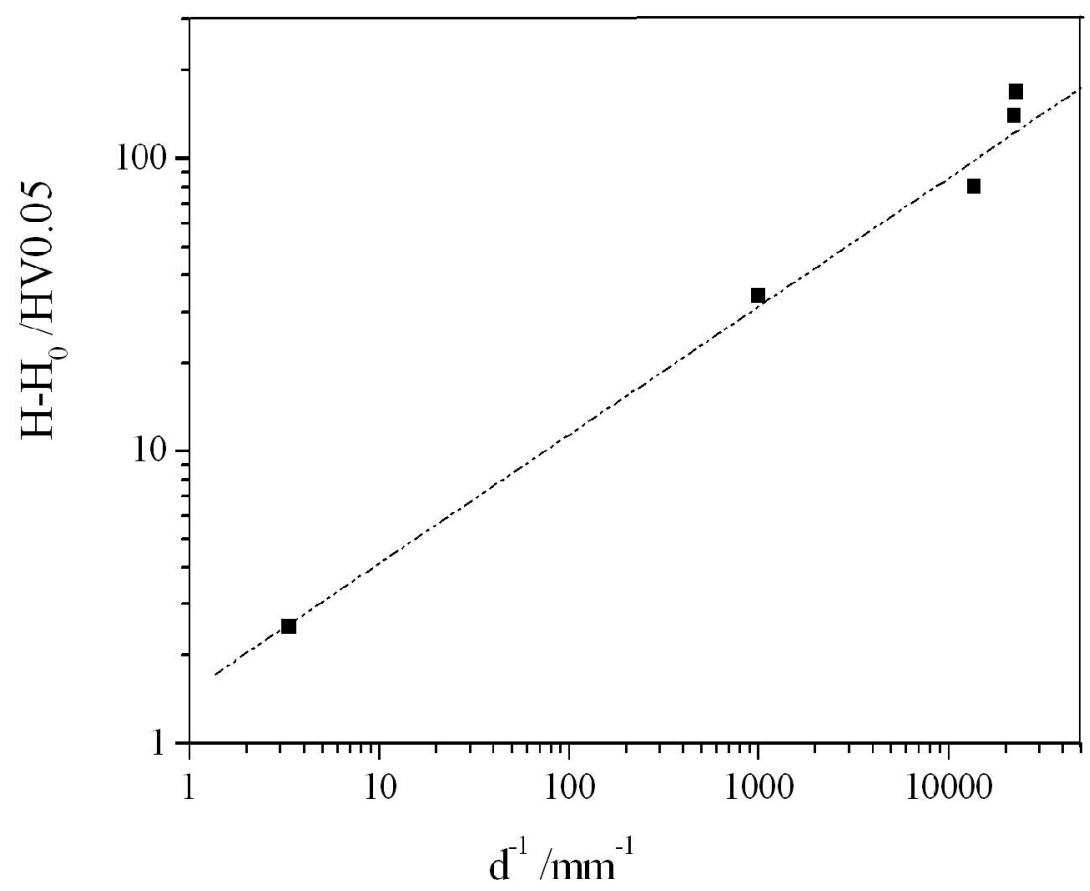

Correlation of grain size and hardness of AIMg4.8 linearised in a Hall-Petch plot after different process routes $279 \times 215 \mathrm{~mm}(150 \times 150 \mathrm{DPI})$ 


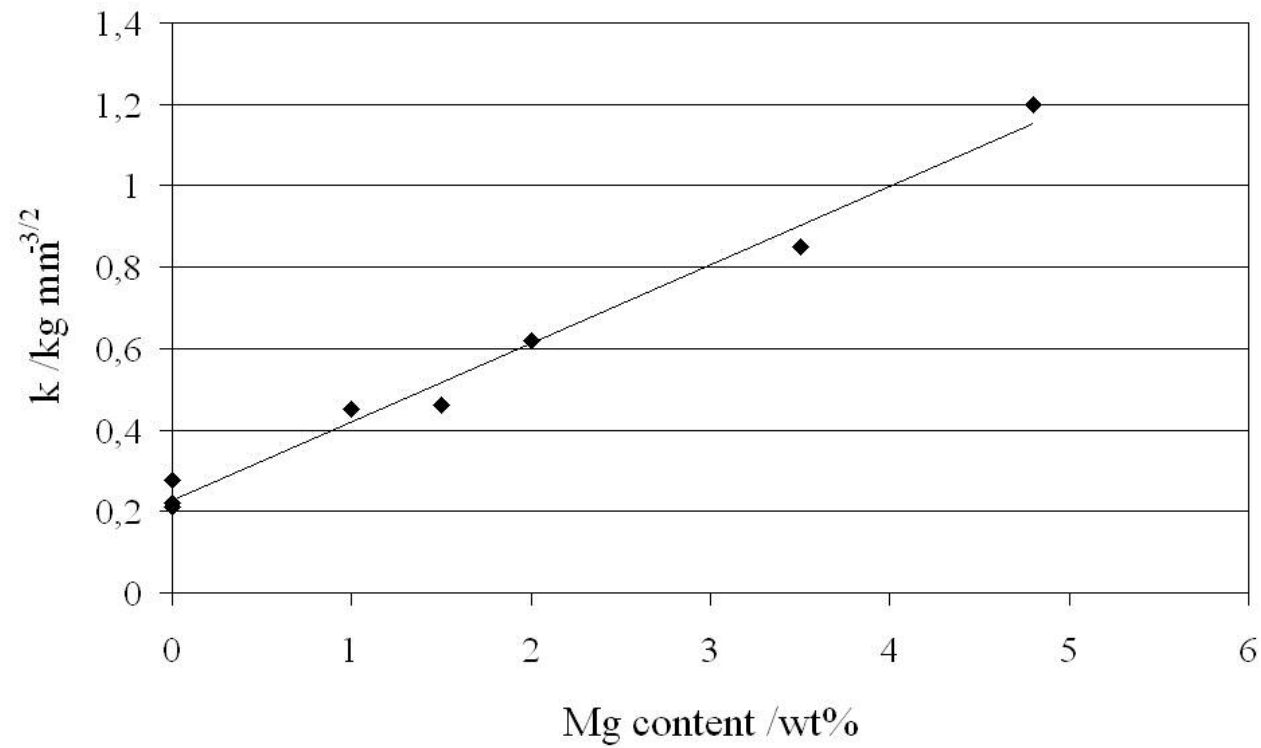

Hall Petch constant $k$ depends on the Mg content; $k$ value of 4.8 wt\% was calculated in the present work while the other results are reported in literature [37-39] $342 \times 213 \mathrm{~mm}(72 \times 72 \mathrm{DPI})$ 


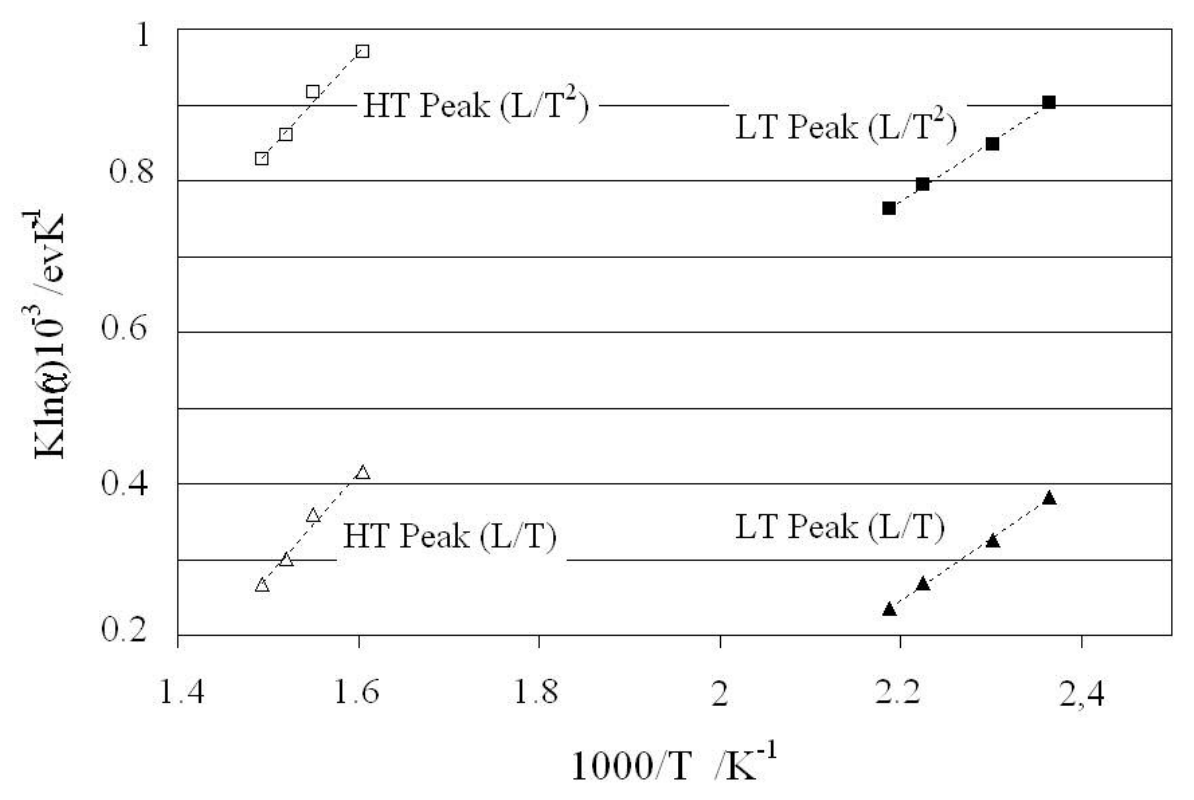

Kissinger plot indicating the activation energy for grain growth 


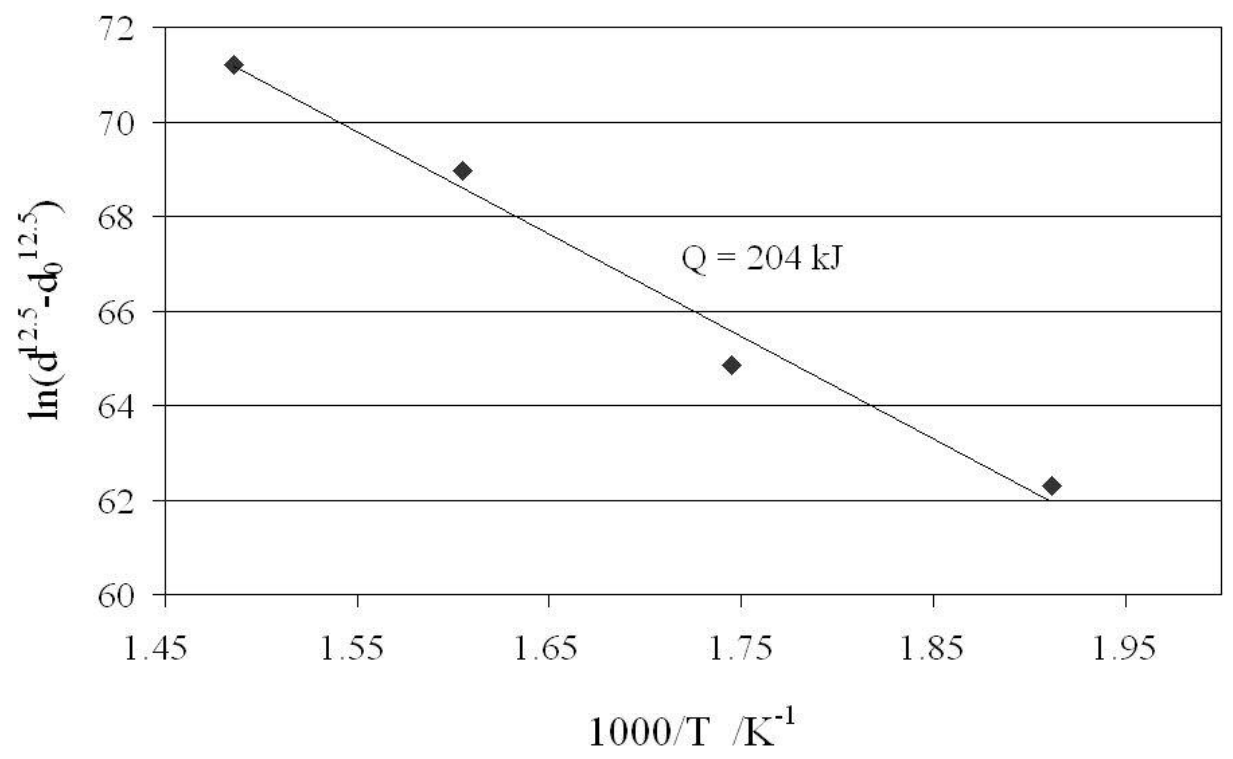

Arrhenius plot of rate constant values obtained by the growth results $342 \times 213 \mathrm{~mm}(72 \times 72$ DPI) 


\begin{tabular}{|l|l|l|l|l|l|l|l|l|l|}
\hline Elements & $\mathrm{Si}$ & $\mathrm{Fe}$ & $\mathrm{Cu}$ & $\mathrm{Mn}$ & $\mathrm{Mg}$ & $\mathrm{Cr}$ & $\mathrm{Ni}$ & $\mathrm{Ti}$ & $\mathrm{Al}$ \\
\hline $\begin{array}{l}\text { AlMg4.8-0 } / \mathrm{wt} \% \\
\text { as-sprayed }\end{array}$ & 0.045 & 0.070 & 0.007 & 0.002 & 4.77 & 0.002 & 0.01 & 0.005 & Balance \\
\hline $\begin{array}{l}\text { AlMg4.8-32 } / \mathrm{wt} \% \\
\text { after 32 milling }\end{array}$ & 0.048 & 0.078 & 0.005 & 0.003 & 4.76 & 0.002 & 0.01 & 0.005 & Balance \\
\hline
\end{tabular}




\begin{tabular}{|l|l|l|l|}
\hline Milling time /h & $\mathrm{H} / \mathrm{ppm}$ & $\mathrm{N} / \mathrm{ppm}$ & $\mathrm{O} / \mathrm{ppm}$ \\
\hline $0 / 8 / 32$ & $36.5 / 44 / 62$ & $11 / 22 / 45$ & $581 / 1117 / 2009$ \\
\hline
\end{tabular}




\begin{tabular}{|l|l|l|l|l|}
\hline Heating rate $/ \mathrm{K} / \mathrm{min}$ & 5 & 10 & 20 & 30 \\
\hline T P1 & 149,6 & 161,1 & 176,3 & 183,9 \\
\hline T P2 & 349,6 & 371,8 & 384,4 & 396,3 \\
\hline
\end{tabular}




\begin{tabular}{|l|l|l|l|l|}
\hline Peak designation & LT-peak & HT-peak & \\
\hline Approach & $\alpha=\mathrm{L} / \mathrm{T}$ & $\alpha=\mathrm{L} / \mathrm{T}^{2}$ & $\alpha=\mathrm{L} / \mathrm{T}$ & $\alpha=\mathrm{L} / \mathrm{T}^{2}$ \\
\hline $\mathrm{eV}$ & 1,30 & 1,24 & 2,16 & 2,08 \\
\hline $\mathrm{kJ} / \mathrm{mol}$ & 126,03 & 120,20 & 209,47 & 200,92 \\
\hline
\end{tabular}

